\section{The Evolution of Living Organisms}

Edited by Prof. G. W. Leeper. (A Symposium to mark the Centenary of Darwin's "Origin of Species" and of the Royal Society of Victoria, held in Melbourne, December, 1959.) Pp. v +459. (Melbourne: The University Press; London: Cambridge University Press, 1962.) 126s. net.

T HIS interesting volumo includes thirty-six contributions from workers distinguished in a wide variety of fields including evolution, genetics, and population dynamics. The volume is divided into two parts of approximately equal length. In the first part, twenty papers are collected under the heading, "Evolution and Selection". Although the scopo and content of these papers differ very widely they are impressive contributions in their respective fields. The first paper, "Accident or Design, the Paradox of Evolution", by E. Mayr, is a brief, but important, summary of the history of ideas on the origin of adaptation. As Mayr points out, evolutionists are now closer in thoir thinking and in their entire interpretation of evolutionary events to the Darwin of 1859 than they have been at any time in tho past hundred years. Some of the other papers deal with very restricted aspects of the subject, for example, chromosome breakage in Astroloma and effect of chromosomo inversions on size and viability of grasshoppers, while others, such as those on the origin of life, the evolution of dominance, and the survival of the mediocre, are clearly of more general interest.

The 16 papers included in the second part of the volume are concerned with the distribution and evolution of the Australasian fauna and flora, and provide a wealth of dotailed information indispensable to anyone with an interest in the fauna and flora of this area.

In considering the origin and distribution of the animals and plants of the southern continents, one's attitude to the theory of continental drift becomes crucial in a sense that it scarcely ever does when dealing with groups rostricted to the northern hemisphere, where the movements of the continents relative to one another have been much less. Acceptance or non-acceptance of the theory of continental drift not only affects at various levels the mannor in which factual evidence of past and present distributions is interpreted, but it also seriously affocts conceptions about the phylogeny of many groups.' For these reasons it seems a pity that more attention has not been directed to this basic problem, although the fow authors who have touched on it seem to reject the possibility of continental drift.

H. E. Hinton

\section{Symbiotic Associations}

Thirteenth Symposium of the Society for General Microbiology held at the Royal Institution, London, April 1963. Edited by P. S. Nutman and Barbara Mosse. Pp. $x+356$. (London: Cambridge University Press, 1963.) 50s.; 9.50 dollars.

T HE Socioty for General Microbiology has a welldeserved reputation for its symposia. They are planned to cover a wide field and to point toward future developments, and not simply to summarize existing knowledge on a narrow topic. This, on symbiosis in microorganisms, is another worthy successor in the series. It shows both the strength and weakness of this approach. The topics range from bacteriophages to lichens. Every microbiologist will surely find fascinating now facts on material which is unfamiliar to him. This wide appeal is tho result of the wide range. The weaknesses are also apparent. Few of the articles are dotailed and up-to-theminute reviews of the kind that are so much in demand nowadlays. This is expected as a necessary consequenee of the general policy of these symposia. Howevor, more serious defects are soon in a fow of the contributions. In some the subject-matter has not been related carefully to the problem of symbiosis. This is particularly marked in the section on bacteriophages. In others the theory of symbiosis is skimmed over. The standard of writing is nevertheless commendable, and nearly all the articles are easy to follow.

The chapters fall into three sections. First, there is an introduction by R. Dubos and A. Kessler. This, on general factors of symbiosis, is stimulating but not very clearly written. The second section is entitled "Plant Associations". It includes sections on lichens (surely among the most remarkable forms of life), on legume nodules, and on mycorrhiza. The third section is on animal associations, many of which are fascinating, for example the symbionts of insects, discussed by Marion A. Brooks, and the chapter on algae and invertebrates by M. R. Droop. J. M. Baker contributes a fine chapter on the ambrosia beetles and their fungi. Two articles deal with associations in the rumen. The book is well produced, and errors are commendably few.

P. H. A. SNeath

\section{Quantum Statistical Mechanics}

Green's Function Methods in Equilibrium and Nonequilibrium Problems. By Dr. Leo P. Kadanoff and Dr. Gordon Baym. (Frontiers of Physics: a Lecture Note and Reprint Series.) Pp. xi +203 . (New York: W. A. Benja min, Inc., 1962.) 4.95 dollars, paper; 6.95 dollars, cloth.

HE principal problem of quantum statistical mech anics is the many-body problem. It consists essentially of finding methods for evaluating equilibrium and nonequilibrium characteristics of large assemblies of particles. Recently new methods for investigating this problem have been developod which are based on the mathematical techniques of quantum field theory. One of the most effective of these techniques is the quantum mechanical Groon's function method developed by Martin and Schwinger. This book consists of a set of lectures on this Green's function method by two of their former students.

In all, there are thirteen chapters. The first five are devoted to the original work of Martin and Schwinger on the equilibrium Green's function and to methods for deriving approximations to the Green's function. The following six chapters outline a theory of non-equilibrium phenomena, including a generalization of Boltzmann's equation with applications to sound propagation and the Landau theory of Fermi liquids. These six chapters owe much to the original research of the authors. The last two chapters discuss the use of the shielded potential to describe a Coulomb gas and the application of the two-body scattering matrix approximation to systems with short-range interactions.

Being essentially a collection of lecture notes the style is informal and at times brief, with an emphasis put on a mathematical analysis of the problems discussed. There is no index and, except for a list of supplementary reading matter at the end, there are fow references. The lectures are suitable only for the serious student of statistical mechanics who is familiar with quantum mechanics and with second quantization. Such a student should find this a usoful addition to his library. The book would be of little use to the student who wishes only to apply statistical mechanical results to specific probloms. F. J. SMrre

\section{Abstract Harmonic Analysis}

By Prof. Edwin Hewitt and Prof. Kenneth A. Ross. Vol. 1: Structure of Topological Groups-Integration Theory-Group Representations. (Die Grundlehron der Mathomatischen Wissonschaften, Band 115.) Pp. viii + 519. (Berlin: Springer-Verlag, 1963.) 76 D.M.

$\mathrm{T}$ the theory of Fourier series one deals with poriodic functions, which may be considered as functions defined on a circle, with the circular functions sine and cosine taking a special rolo. The subject of this book, abstract harmonic analysis, can be regarded as a vast genoralization of tho theory of Fourier sories in which the circle is replaced by any topological group, which is either compact or locally compact and Abelian. (The case of a non-Abelian group, which is only 